\title{
Students' Attitudes About the Ethics of Using Animals for Experimental Purposes
}

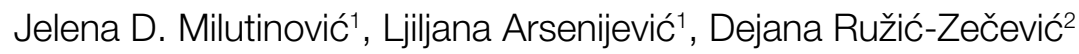

\begin{abstract}
This study aims at discovering the ethics level of the students who are attending the Faculty of Medical Sciences, the Faculty of Engineering Sciences and postgraduate students with experience of use laboratory animals in experimental purposes at University of Kragujevac. Focus of this study is on ethical segment of use of laboratory animals for experimental purposes and the correlation between the manifested level of ethics and various other factors like gender, high-school education, GPA (grade point average), educational level of parents and desired affiliation after the graduation.

The cross sectional study was conducted with 175 participants. In data collection, a questionnaire was used consisting of questions concerning sociodemographical characteristics and two scales - Gallup and Beckstead's scale and a scale specially designed for the purposes of this research. The data were processed by using the methods of descriptive statistics, t-test for independent samples, single factor analysis of variance and Pearson's correlation coefficient.

The results have shown that the correlation between the manifested level of ethics of using animals in experimental purposes and gender, high-school education, grade point average, field of study or desired affiliation after the graduation is statistically significant. The differences in the results between students of pharmacy and the students of engineering sciences are also statistically significant. Cronbach's alpha were estimated at 0.786 , which implies that the internal consistency of scales shows significantly high level of reliability. The students from both fields, pharmacy and mechanical engineering, have shown a considerable level of ethics concerning the use of animals for laboratory purposes.
\end{abstract}

Key words: ethics, laboratory animal, attitude
(1) Faculty of Medical Sciences, University of Kragujevac, Serbia.

(2) Department of Pharmacology and Toxicology, Faculty of Medical Sciences, University of Kragujevac, Kragujevac, Serbia.

\section{Correspondence:}

JELENA MILUTINOVIĆ

E: jecamilutinovic92@gmail.com M: +381694566146

\section{ARTICLE INFO}

Received: $25^{\text {th }}$ November 2018 Revision received: $20^{\text {th }}$ December 2018 Accepted: $27^{\text {th }}$ December 2018

\section{INTRODUCTION}

Even though scientific experiments have been constantly contributing to the development of modern science, experiments on live animals have always been a matter of controversy since the ethics of such actions has been often questioned. The principles of modern ethics, oriented towards biocentrism, require that experiments conducted on animals should be reduced in number as much as possible and that they should be performed taking into consideration the welfare of animals so that the animals' pain, suffer, fear and stress are minimalized. ${ }^{1}$
The ethical experiments involving the procedures of manipulation with experimental animals aim at the acquisition of new knowledge in the field of biomedicine and pharmacology, and thus they contribute to a general development of medicine and pharmacology. ${ }^{2}$ These procedures include the deliberate sacrifice of experimental animals in order to get isolated organs or to sacrifice an animal at the end of the experiment. The death of animals must occur in an instant (the procedures which meet this criterion include the triple dose of anesthetics, inhalation of 
$\mathrm{CO} 2$ or other gases in special chambers, cervical dislocation, decapitation, etc.) and must not cause suffering or pain to an animal. ${ }^{2}$

According to the data obtained by World Society for the Protection of Animals (WSPA) by the end of 2006, only 65 countries out of 120 had national legislation dealing with legal aspects of animal protection. ${ }^{3}$ The first law concerning the animal welfare was adopted in Republic of Serbia in 2009. The Animal Welfare Act regulates the number of important issues concerning the preservation and the promotion of animal welfare in various situations, including the use of animals in experimental or other scientific purposes which may cause injury, pain, suffering, fear and stress to an animal, impair its health and cause permanent or temporary disruption of physical, psychological, or genetic integrity and finally result in its death. ${ }^{4}$

The attitudes of individuals concerning this matter, and ethics in general, mainly arise from their attitudes towards the consequences of such actions, normative beliefs about the expected behaviour and controlling beliefs regarding the feasibility of conduct. ${ }^{5}$ Attitudes towards animals are influenced by many psychological factors. An insight into the attitudes can be obtained by using various different data collection methods such as a questionnaire. $6^{6,7}$

A review of national academic and scientific literature leads to a conclusion that there is a relatively small number of studies dealing with this aspect of ethics in medical workers and students. The idea for this research arose from this particular deficiency.

Assuming that this topic did not get the attention it deserves and that there is no a 'sufficient' level of awareness among the general population, the study was conducted on two groups of university students. The students of the first group study medical sciences whereas the students of the second group study technical sciences.

The objective of this paper is to determine the level of ethics among the students attending the Faculty of Engineering Sciences (students do not have any laboratory experience), the Faculty of Medical Sciences (which students have had contact with laboratory during their studies and who have learnt about experiments on animals) and postgraduate students (who have almost everyday experience with laboratory animals) and the correlation between that level and various other factors like gender, high-school education, GPA (grade point average), educational level of parents and desired affiliation after the graduation.

\section{METHODS}

The research is conducted on participants who attend the Faculty of Medical Sciences and the Faculty of Engineering Sciences at University of Kragujevac. It includes 175 participants, among them 62 males and 113 females. This study has three groups: 73 students who attend the Faculty of Engineering Sciences, 78 students who attend the Faculty of Medical Sciences, and 24 postgraduate students.

This study is observational and its methodology corresponds to a study of prevalence where the participants are filling in a questionnaire at the same time. The participants involved in this study participated voluntarily and anonymously.

For data collection, a questionnaire is used consisting of 3 parts and general part referring to some basic information about the study itself (Appendix 1). The first part consists of questions about the sociodemographic characteristics of the participants (gender, age, high-school education, GPA, desired affiliation after graduation, the educational level of their parents and whether they have a pet). The second segment is Gallup and Beckstead scale (from 1988), ${ }^{8}$ which was reused in Metzger's study (2014), ${ }^{9}$ while the third part is dedicated to a scale designed for the purposes of this research.

Respondents were asked to indicate (in the second, third and the fourth part of the questionnaire) the degree of agreement with each statement on the Likert's scale, from 1 (completely disagree) to 5 (totally agree). The final score was calculated by adding points for separate statements thus obtaining the total score. Then, as in original studies, the mean value was determined. Higher means values indicate a higher level of ethics. Similarly, the statements considered as negative attitudes towards the issue were scored inversely in respect to those which speak 
positively. This procedure is often used in order to avoid the tendency of respondents to consistently agree or disagree with statements. In Gallup and Beckstead's scale, such statements were under the numbers $3,4,6,8,10,11,12,14$, and in the scale designed for this particular research under the numbers 2 and 5 . In the fourth part of the questionnaire, each claim was scored individually and then the mean value was obtained. For the second part of the questionnaire, the total number of points that a respondent could have achieved on the scale ranged from 14 to 70 with higher scores implying a higher level of ethics, while in the third part, the score ranged from 9 to 45 .

This study has investigated whether there is an impact of gender, type of high-school education, the field of study at university and prior knowledge on the subject, grade point average, desired

\section{RESULTS}

During the winter semester of the school year 2014/2015, 180 respondents (the students of integrated academic studies of pharmacy and postgraduate students from the Faculty of Medical Sciences and the students from the Faculty of Engineering Sciences) underwent the interviewing. 175 questionnaires out of 180 were filled in and returned (the percentage of answers 97.22\%). The average age of the participants amounts $21.5 \pm 1.489$.

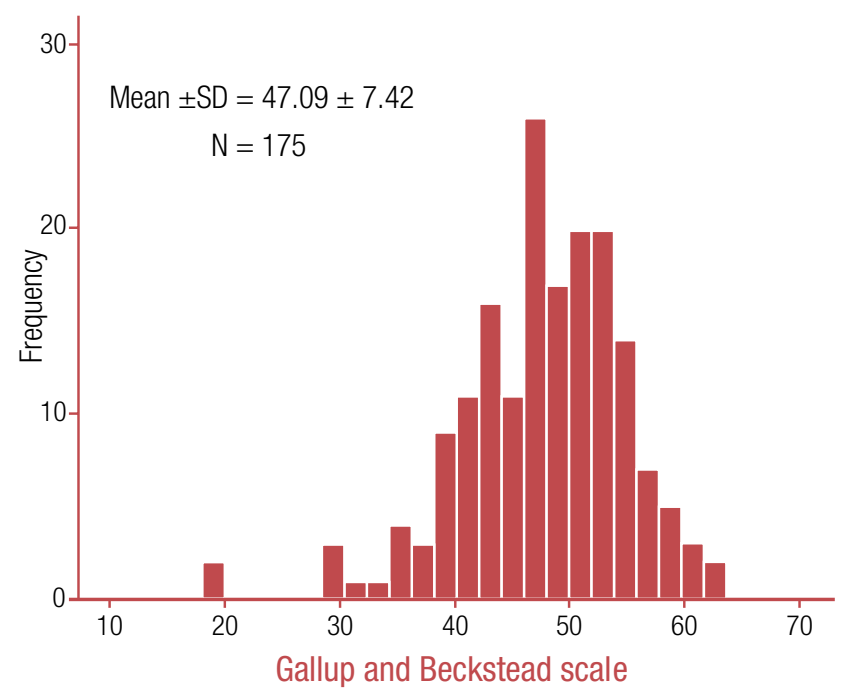

Figure 1: Frequency distribution for the Gallup and Beckstead's scale affiliation after graduation, owning a pet and the educational levels of parents (which in this case are independent variables) on the level of ethics concerning the use of experimental animals for laboratory purposes in students (dependent variable, outcome).

The statistical analysis of the data was conducted by using the software package IBM SPSS Statistics v20. The results were obtained through the methods of descriptive statistics (perceptual distribution, mean and standard deviation). In order to determine the influence of individual factors on the ethics a t-test for independent samples and single factor analysis of variance (ANOVA) were used. The results were considered statistically significant if the probability of the null hypothesis (p) was < 0.05. Pearson's correlation coefficient was used to determine the relationship between quantitative variables.

Results for the Gallup and Beckstead scale and the scale designed for this research are presented in Tables 1, 2 and 3 in the form of mean values and standard deviations. The frequency distribution histograms are shown in Figures 1 and 2.

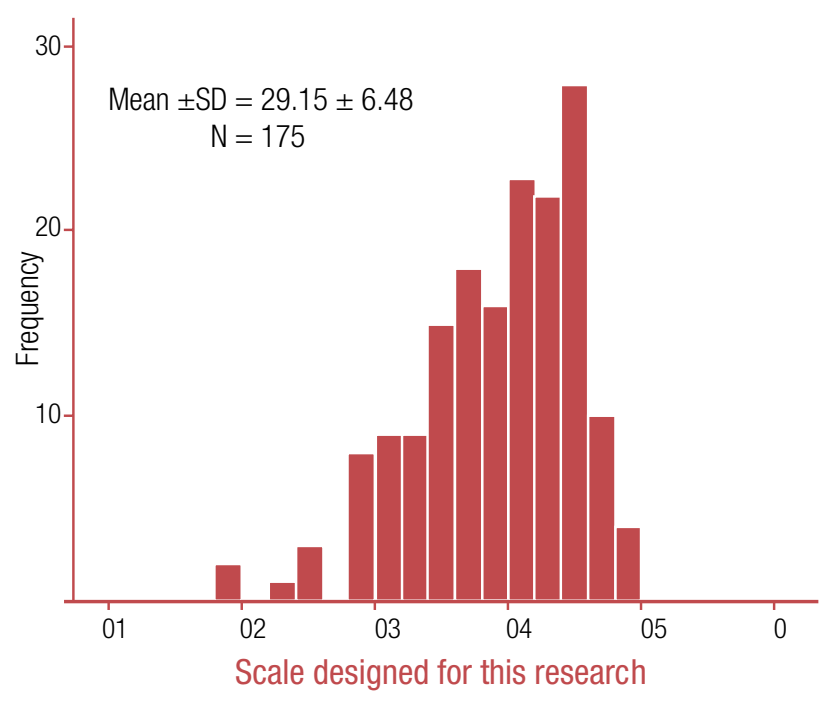

Figure 2: Frequency distribution for the scale designed for this research 
Table 1: Results for all participants $(n=175)$

\begin{tabular}{lccc}
\hline & Gallup and Beckstead scale & The scale designed for this research \\
\hline Mean value and standard deviation & $47.09 \pm 7.42$ & 19 & $29.15 \pm 6.48$ \\
\hline Minimal values & & 62 & 9
\end{tabular}

Table 2: Results for the scales in respect to participant characteristics

\begin{tabular}{|c|c|c|}
\hline & Variable & Number of participants \\
\hline \multirow{2}{*}{ Gender } & Male & $62(35.4 \%)$ \\
\hline & Female & $113(64.6 \%)$ \\
\hline \multirow{2}{*}{ High-school education } & Medical high-school & $71(40.6 \%)$ \\
\hline & Other schools & $104(59.4 \%)$ \\
\hline \multirow{3}{*}{ A University student attends } & Faculty of Medical Sciences & $78(44.6 \%)$ \\
\hline & Faculty of Engineering Sciences & $73(41.7 \%)$ \\
\hline & Postgraduate student & $24(13.7 \%)$ \\
\hline \multirow{7}{*}{ GPA } & $<7.0$ & $0(0 \%)$ \\
\hline & $7.01-7.5$ & $11(6.3 \%)$ \\
\hline & $7.51-8.0$ & $37(21.1 \%)$ \\
\hline & $8.01-8.5$ & $37(21.1 \%)$ \\
\hline & $8.51-9.0$ & $52(29.7 \%)$ \\
\hline & $9.01-9.5$ & $31(17.7 \%)$ \\
\hline & $>9.51$ & $7(4.0 \%)$ \\
\hline \multirow{7}{*}{ Desired affiliation after the graduation } & Working in a pharmacy, clinical pharmacist & $43(24.6 \%)$ \\
\hline & Working as pharmaceutical company representative & $13(7.4 \%)$ \\
\hline & Working in academic and scientific research sector & $37(21.1 \%)$ \\
\hline & Working in education sector & $24(13.7 \%)$ \\
\hline & Working in the production of medicines sector & $8(4.6 \%)$ \\
\hline & Working in the medicines' quality control sector & $1(0.6 \%)$ \\
\hline & Other & $49(28.0 \%)$ \\
\hline
\end{tabular}

The differences in ethics in respect to gender

In order to find an answer to the question of whether there is a difference in the level of ethics among students of different gender a t-test for independent samples is used. Females achieved slightly higher average scores on the Gallup and Beckstead scale $(48.04 \pm 6.247)$ in respect to males $(45.34 \pm 8.977)$, t-test indicated that this difference is statistically significant $(t=-2.109$; $\mathrm{p}=0.038$ ). Regarding the scale designed for the purpose of this research, female participants achieved a slightly higher average score (30.04 $\pm 5.755)$ in comparison to males $(27.55 \pm 7.410)$, and this difference was statistically significant too $(\mathrm{t}=-2.291 ; \mathrm{p}=0.024)$.
The differences in ethics in respect to high-school education

A t-test for independent samples was used for determining the potential links between the ethics level of the students and their high-school education. The students who attended medical high school (50.37 \pm 5.254$)$ had higher average scores for the Gallup and Beckstead scale in respect to students who have completed other high-schools (44.85 \pm 7.859 ). However, the statistical tests show that the difference is statistically significant $t(175)=5.568 ; p=0.00$. In case of the scale designed for this research, students who completed medical schools $(32.23 \pm 4.079)$ have also shown higher average score in respect 
Table 3: Results on the scales in respect to education of parents and owing a pet

\begin{tabular}{|c|c|c|}
\hline & Variable & The number of participants \\
\hline \multirow{6}{*}{ Mother's educational level } & Elementary school not completed & $1(0.6 \%)$ \\
\hline & Elementary school & $8(4.6 \%)$ \\
\hline & High school & $98(56.0 \%)$ \\
\hline & College & $19(10.9 \%)$ \\
\hline & University & $46(26.3 \%)$ \\
\hline & Other, unknown & $3(1.7 \%)$ \\
\hline \multirow{6}{*}{ Father's educational level } & Elementary school not completed & $1(0.6 \%)$ \\
\hline & Elementary school & $10(5.7 \%)$ \\
\hline & High school & $100(57.1 \%)$ \\
\hline & College & $26(14.9 \%)$ \\
\hline & University & $37(21.1 \%)$ \\
\hline & Other, unknown & $1(0.6 \%)$ \\
\hline \multirow{2}{*}{ The owner of a pet } & No & $83(47.4 \%)$ \\
\hline & Yes & $92(52.6 \%)$ \\
\hline
\end{tabular}

to students who finished other high schools $(27.06 \pm 6.978)$. The t-test proves that there is a statistically significant difference between the two groups of students $t(175)=6.165 ; p=0.00$.

\section{The differences in ethics in respect to the field of} study

To determine whether there is a difference in ethics level among the students in respect to the faculty they attend, an ANOVA was used. The objective of this paper was to determine the level of ethics among the students attending the Faculty of Engineering Sciences (students who do not have any laboratory experience), the students from Faculty of Medical Sciences (students have seen laboratory during their studies and have learnt about experiments on animals) and postgraduate students (postgraduate students and students who volontire in laboratory - who have almost everyday experience with laboratory animals). In both cases, Gallup and Beckstead scale and the scale designed for this research, statistically significant relation was found $(\mathrm{F}=35.853$; $\mathrm{p}=0.000$ and $\mathrm{F}=42.183 ; \mathrm{p}=0.000$, retrospectively). Results for both scales are presented in Figure 3.

The difference in ethics in respect to desired affiliation after graduation

ANOVA was used in order to determine whether there is a statistically significant difference between the level of ethics and desired affiliation of students. In Gallup and Beckstead scale and in the scale designed for this research, statisti- cally significant relation was found $(\mathrm{F}=3.473$; $\mathrm{p}=0.003$ and $\mathrm{F}=7.283 ; \mathrm{p}=0.000$, retrospectively). The results for both scales are presented in Figure 4.

Students who want to work with patients directly have higher average scores on the Gallup and Beckstead scale (50.67 \pm 5.437$)$ compared to students who wish to engage in any other job positions (45.92 \pm 7.619$)$ and this difference is statistically significant $(\mathrm{t}(175)=4.481 ; \mathrm{p}=$ o.00o). On the scale designed for this research, students who want to work with patients have also higher average scores on the scale $(32.81 \pm$ 4.553) than those who do not $(27.96 \pm 6.581)$. The difference is statistically significant $\mathrm{t}(175)=$ $5.391 ; \mathrm{p}=0.000$.

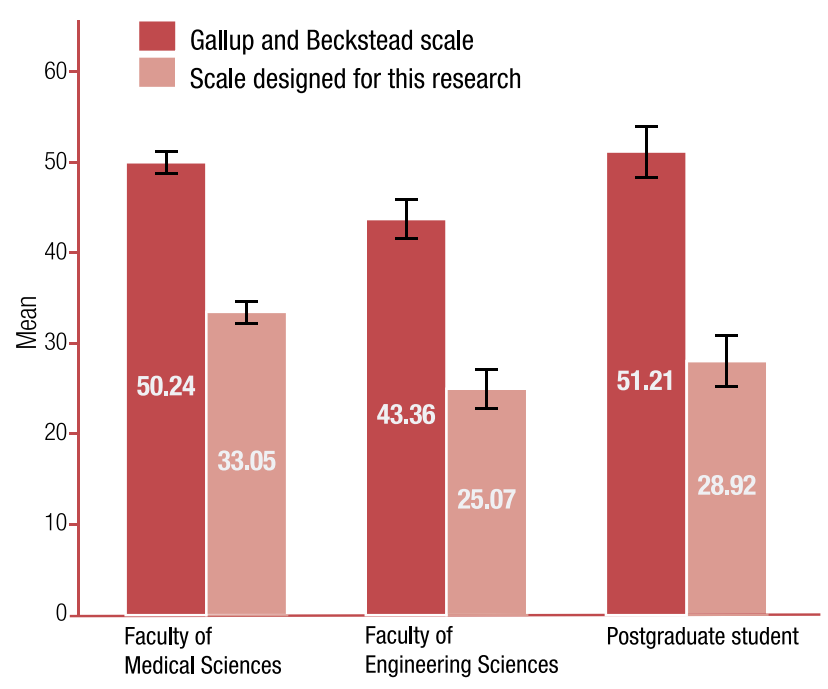

Figure 3: Results for scales in respect to the field of study 


\section{The differences in ethics in respect to GPA}

In order to determine the relationship between the average point grades and scores on the scales designed to evaluate the level of ethics, Pearson's correlation coefficient was used. The results have shown that there is statistically significant correlation between GPAs and scores on Gallup and Beckstead scale $(\mathrm{r}=0.235 ; \mathrm{p}=0.002)$ - correlation is significant at the 0.01 level (2-tailed). In case of the scale designed for this research, the relation is also statistically significant $(\mathrm{r}=$ $0.208 ; \mathrm{p}=0.006)$ - correlation is significant at the 0.01 level (2-tailed). Finally, a conclusion can be drawn that there is significant correlation between the level of ethics and GPA.

The differences in ethics and parents education Single factor analysis of variance (ANOVA) was used to determine the correlation between the ethics level and the education of parents for both parents separately. The results show that in both cases, on Gallup and Beckstead and the scale designed for this research, the correlation between the education of fathers and the ethics is not statistically significant $(\mathrm{F}=0.610, \mathrm{p}=0.692$ and $\mathrm{F}=0.525, \mathrm{p}=0.757$, respectively). Statistically significant difference in ethics depending on the educational level of mothers+ is shown for scale designed for this research $(F=3.374, p=0.006)$ and there is no statistically significant difference for Gallup and Beckstead scale in correlation between the education of mothers and the ethics ( $F$ $=1.912, \mathrm{p}=0.095$ ).

The differences in ethics in respect to owning a pet A t-test for independent samples was used to determine if there is a correlation between the ethics of using animals in experimental purposes of a person and the fact whether a person owns a pet. Students who own a pet had slightly higher average scores on Gallup and Beckstead scale (47.27 \pm 6.243$)$ in comparison to those who do not $(46.88 \pm 8.573)$. On the scale designed for this research, the students who own a pet had a slightly higher average scores (29.74 \pm 5.902 versus $28.51 \pm 7.046)$. In both cases, the results of the t-test have shown that there is no statistically significant correlation $(\mathrm{t}(175)=-0.348 ; \mathrm{p}$ $=0.728$ and $\mathrm{t}(175)=-1.259 ; \mathrm{p}=0.210$, respectively).

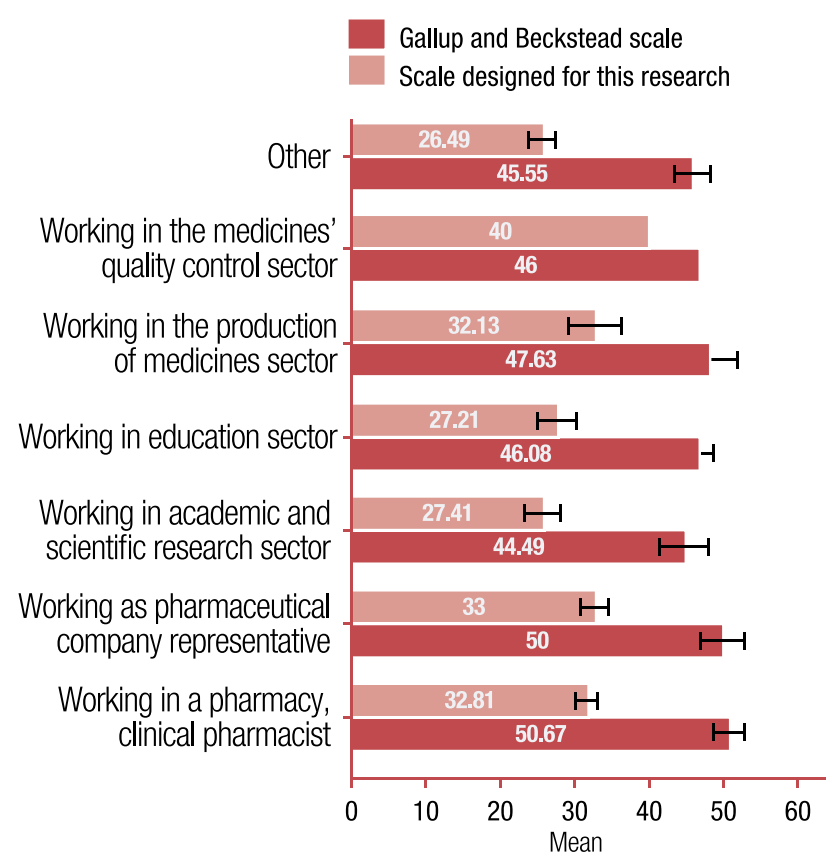

Figure 4: Results for both scales in respect to desired affiliation after the graduation

The results of this study obtained through fourteen one-sample t-tests

The results of this study, obtained through fourteen one-sample t-tests, for each individual point on the scale, are presented in Table 4. The results have a confidence interval of $95 \%$ which indicates that the level of significance is 0.05 .

The evaluation of competitive validity and reliability of the questionnaire scale designed for this research

In order to determine the competing validity between Gallup and Beckstead scale and the scale designed for this research we used Pearsons' correlation coefficient. The results show that there is a statistically significant and strong positive correlation between the results on Gallup and Beckstead scale and the scale of this research ( $\mathrm{r}$ $=0.208 ; \mathrm{n}=175 ; \mathrm{p}=0.006$ ). This can be taken as an evidence that there is a competitive validity. The significance interval of 0.01 implies that the confidence interval is $99 \%$. The diagram showing the distribution of the correlation between these two variables, with the regression line and the equation, is presented in Figure 5.

The reliability of the measuring instrument is a metric characteristic which indicates the extent to which the same results can be expected when the same measuring device is reused in future 
Table 4: Results of the study

\begin{tabular}{|c|c|c|}
\hline & Question & \\
\hline 1. & Research on animals has little or no bearing on problems confronting people. & 2.73 \\
\hline 2. & An intrinsic interest in the animal for its own sake is sample justification for doing animal research. & 3.10 \\
\hline 3. & I am very concerned about pain and suffering in animals. & 3.56 \\
\hline 4. & I would rather see humans die or suffer from disease than to see animals used in research. & 1.72 \\
\hline \multirow[t]{2}{*}{5.} & Since many important questions cannot be answered by doing experiments on people, we are left with no alternative & 3.71 \\
\hline & but to do animal research. & \\
\hline 6. & I have seriously considered becoming a vegetarian in an effort to save animal lives. & 2.13 \\
\hline 7. & New surgical procedures and experimental drugs should be tested on animals before they are used on people. & 3.86 \\
\hline 8. & There are plenty of viable alternatives to the use of animals in biomedical and behavioral research. & 3.63 \\
\hline 9. & Many important biomedical breakthroughs are a consequence of animal research. & 3.94 \\
\hline 10. & Animals should be granted the same rights as humans. & 2.98 \\
\hline 11. & Most psychological research done on animals is unnecessary and invalid. & 2.88 \\
\hline 12. & We need more regulations governing the use of animal research. & 3.82 \\
\hline 13. & Most laboratory animals are better housed, fed, cared for, and protected from pain and suffering than many humans. & 3.28 \\
\hline 14. & Animal research cannot be justified and should be stopped. & 2.20 \\
\hline
\end{tabular}

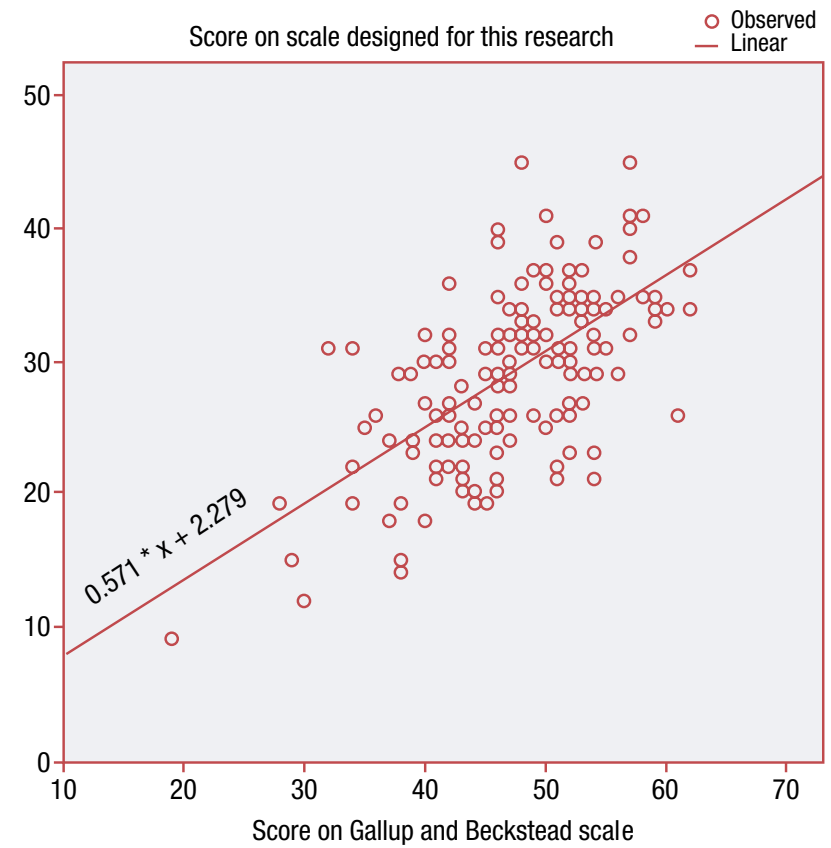

Figure 5: The correlation between the results obtained through this research and Gallup and Beckstead's scale

studies. The most commonly used method for evaluating the confidence interval is to calculate it by using the reliability of internal consistency, i.e. by calculating the Cronbach's coefficient alpha, where the coefficient value $\geq 0.7$ is considered to be a good indicator of reliability (0.7 $\leq \alpha \leq$ 0.9). Cronbach's alpha were estimated at 0.786 , which implies that the internal consistency of scales is significantly high.

\section{DISCUSSION}

The cultural differences, in attitudes towards animals, should be understood and respected in order to promote tolerance in multicultural education. It is shown that European students and U.S. students (though to somewhat lower extent) do not approve cruelty towards animals to the same extent as students from some Asian countries. ${ }^{10}$ The students from Europe have manifested a greater concern about the suffer of animals than Asian students, but not in term of respect towards them. ${ }^{11,12}$

It is generally assumed that female students have greater concern for the suffering of animals and that they express greater care towards their welfare than male students do. This study confirms such hypothesis and our results are consistent with those reported in literature. This hypothesis can also be projected on general population. The female subjects in almost all situations exhibit greater care and a higher degree of empathy towards animals in comparison to male subjects. ${ }^{13-17}$ It is believed that women and men are born with equal potential for the development of empathy and ethics, but that difference exist later in life, as a result of environmental influences, motivation and education. ${ }^{18,19}$ The results of this study confirm the previously mentioned statements since the results have shown that the differences between two genders are statistically significant. This thesis cannot be applied 
to veterinary students whose attitudes are more closely connected to their possession of pets in an early age than to gender differences. ${ }^{20,21}$

This study has shown the statistically significant correlation between the ethics level and whether the students want to engage in direct contact with patients or not at their desired job position. Due to working in a pharmacy or working as a clinical pharmacist, the individual is in direct contact with patients in relation to other affiliations offered. Therefore, it was assumed that the level of ethics and empathy could be related to desired affiliation or, to be more precise, with a fact whether an individual desires to work with patients. ${ }^{22-24}$ which has been shown in this study according to the results because there is statistically significant difference between the ethics in respect to the high-school education students completed. The interest in certain field of study and motivation to choose certain professional profile is under the influence of various different factors such as a talent and skills for certain activities, the expected salary, social trends, parental influence, labor market conditions, etc. ${ }^{25}$, ${ }^{26}$ However, it is generally accepted that both working in pharmacy store and as a sales representative require exceptional social skills. This can be one of the reasons why statistically significant correlation between the ethics and the desired affiliation was found.

Family environment in an early age has an influence on later interpersonal relationships. Moreover, it provides a solid basis for the development of empathy and also shapes the sense of ethics. ${ }^{27,}{ }^{28}$ If the level of education is taken as an indicator of the awareness of the issue, then it is expected that sense of ethics towards animals is passed to the offspring and their attitudes can have a strong influence on the attitudes a child would have. This study has shown that there is no statistically significant difference between the levels of empathy students have towards animals and parental education, except statistically significant correlation between the results on scale designed for the purpose of this research and education of mothers.

Gallup and Beckstead conducted a research including 263 students from different departments of the State University in New York in 1988. One of the conclusions of this study is that there is some degree of concern for the welfare of animals used in scientific experiments but also that there is a need to evaluate the real neces- sity of conducting such research experiments. ${ }^{8}$ Metzger replicated the previously mentioned research to determine whether there was a change in students' attitudes towards experiments which use animals due to a constant declining public support for their realization. ${ }^{9}$

The assessment of the points given in the questionnaire should enable the evaluation of whether the decline in value of the point is a result of a growing concern for animals and/or a declining assumed values of using animals in research.[9] The data from the Gallup and Beckstead study were published as a frequency of response, and then transferred to average value of every point with one-sample t-tests. Fourteen one-sample t-tests were also carried out in the study conducted by Metzger. In Metzger's study, there is a statistically significant difference (for all points, except for 2 and 13) with the results of Gallup and Beckstead study determined by using the Bonferroni correction, which is $\alpha=0.0035 .{ }^{9}$

The increasing values in different time periods in which the three studies are conducted are noticeable in terms of points given under the numbers 8,10 and 13 . The results obtained in this study are in the range of the previous two studies in terms of points 1, 3, 4, 6, 11 and 14. The other values of the points do not deviate from the results obtained through the previous studies. The results on the points 4, 6, 11 and 14 represent the concern for the animal welfare while the points 5, 7 and 9 express the evaluation of research in which animals are used.

The questionnaire should be used on a greater number of participants, so that psychometric characteristics and the validity of the scale are tested in detail. This study is conducted on a small sample of students attending two faculties, which may be a potential reason why the statistically significant correlation was not found in all parameters. Additionally, all the data was collected through self-expression so the reliability of the results relies completely on the honesty and truthfulness of the students.

\section{CONCLUDING REMARKS}

The population of students who participated in this research, from both the Faculty of Medical Sciences and the Faculty of Engineering Sciences, manifested a satisfactory level of ethics. For pharmacists, it is extremely important that in 
addition to theoretical knowledge they acquire through their studies, they also possess a well developed ethics and the sense of empathy towards the animals they use in their experiment. The empathy for experimental animals helps them judge the rationality of their experimental undertakings and prevents them from victimizing animals without a real necessity. Moreover, the empathy for animals is just an integral part of the empathy towards living beings in general, including the other people. Even for those pharmacy students who will not work in academic and scientific field in the future, and thus probably will not be in position to work with laboratory animals the empathy towards animals is extremely important. Empathy, in general, will help them understand their patients better and take a better care of them. In such supportive atmosphere it would be much easier to gain a patient's trust and thus all the relevant information needed in making the decisions about the most rational treatment. The students who participated in this study, at least judging by their empathy towards animals, have a huge potential to become excellent medical workers who would properly treat their patients.

\section{ACKNOWLEDGEMENTS}

We would like to express our special gratitude to the following authors who were kind enough to make their studies available to us and allowed me to use them in our research without any compensation:

- Harold Herzog from the Department of Psychology, Western Carolina University, Cullowhee, USA,

- Gareth Davey from the Psychology Department, University of Chester, UK,

- William J. Ickes a Distinguished Professor of Psychology, University of Texas at Arlington, USA and

- Clive Phillips from the Centre for Animal Welfare and Ethics, University of Queensland, Gatton, Australia.

\section{CONFLICT OF INTEREST}

None.

\section{FUNDING}

The study did not have any sponsor.

\section{REFERENCES}

1. Baticevic A. Eticki i pravni okviri za zastitu dobobiti eksperimentalnih zivotinja u Republici Srbiji. Glasnik Advokatske komore Vojvodine. Advokatska Komora Vojvodine 2012;84(11):726-51.

2. Pravilnik za rad sa eksperimentalnim zivotinjama. Farmaceutski fakultet, Univerzitet u Beogradu, septembar 2008. Available at: http://www.pharmacy.bg.ac.rs/ files/pravilnik-za-rad-sa-eksperimentalnim-zivotinjama.pdf. Last visited: 20.11.2014.

3. Directive 86/609/EEC, Brussels, 1986.

4. Phillips CJC. Effects of field of study on university students' attitudes towards animal issues. Animal Welfare 2014;23:459-66.

5. Izmirli S, Phillips CJC. The relationship between student consumption of animal products and attitudes to animals in Europe and Asia. British Food Journal 2011;113:436-50.

6. Phillips CJB, Izmirli S, Aldavood J, et al. An international comparison of female and male students' attitudes to the use of animals. Animals 2011;1:7-26.

7. World Society for the Protection of Animals: An overwiew of Animal Protection Legislation, 2006. Available at: http://enextranet.animalwelfareonline.org/ resources/animalwelfare/legislation/index.aspx Last visited: 17.12.2014.

8. Gallup GG, Beckstead JW. Attitudes toward animal research. Am Psychol 1988;43:474-6.

9. Metzger MM. Attitudes toward animal research: revisiting Gallup and Beckstead (1988). J Undergrad Neurosci Educ 2014;12(2):154-8.

10. Phillips CJC, Izmirli S, Aldavood SJ, et al. Students' attitudes to animal welfare and rights in Europe and Asia. Anim Welf 2012;21(1):87-100.

11. Li PJ, Davey G. Culture, Reform Politics, and Future Directions: A Review of China's Animal Protection Challenge. Society \& Animals 2012;21(1):34-53.

12. Davey G. Chinese University Students' Attitudes Toward the Ethical Treatment and Welfare of Animals. J Appl Anim Welf Sci 2006;9(4):289-97.

13. Philips CJC, McCullough S. Student attitudes on animal sentience and use of animals in society. J Biol Educ 2005;40:1-8.

14. Signal TD, Taylor N. Attitude to Animals and Empathy: Comparing Animal Protection and General Community Samples. Anthrozoös 2007;20(2):125-30.

15. McKendree MG, Croney CC, Widmar NJ. Effects of demographic factors and information sources on United States consumer perceptions of animal welfare. J Anim Sci 2014;92(7):3161-73.

16. Williams JM, Muldoon J, Lawrence A. Children and their pets: Exploring the relationships between pet ownership, pet attitudes, attachment to pets and empathy. Educ Health 2010;28(1):12-5. 
17. Herzog HA. Gender Differences in Human-Animal Interactions: A Review. Anthrozoös 2007;20(1):7-21.

18. Signal TD, Taylor N. Attitudes to animals: Demographics within a community sample. Soc Anim 2006;14(2):147-57.

19. Ickes W, Gesn PR, Graham T. Gender differences in empathic accuracy: Differential ability or differential motivation? Pers Relatsh 2000;7(1):95-109.

20. Mestre MV, Samper P, Frías MD, Tur AM. Are women more empathetic than men? A longitudinal study in adolescence. Span J Psychol 2009;12(1):76-83.

21. Hazel SJ, Signal TD, Taylor N. Can teaching veterinary and animal-science students about animal welfare affect their attitude toward animals and human-related empathy? J Vet Med Educ 2011;38(1):74-83.

22. Magalhães E, Salgueira AP, Costa P, Costa MJ. Empathy in senior year and first year medical students: a cross-sectional study. BMC Med Educ 2011;11:52.

23. Chen DC, Kirshenbaum DS, Yan J, Kirshenbaum E, Aseltine RH. Characterizing changes in student empathy throughout medical school. Med Teach 2012;34(4):305-11.
24. Tavakol S, Dennick R, Tavakol M. Empathy in UK medical students: differences by gender, medical year and specialty interest. Educ Prim Care 2011;22(5):297303 .

25. Izmirli S, Yigit A, Phillips CJC. Attitudes of Australian and Turkish Students of Veterinary Medicine Toward Nonhuman Animals and their Careers. Soc Anim 2014;22(6):580-601.

26. Paul ES, Serpell JA. Childhood pet keeping and humane attitudes in young adulthood. Animal Welfare 1993;2:321-37.

27. Serpell JA. Factors influencing veterinary students' career choices and attitudes to animals. Anim Welf 2005;32(4):491-6.

28. Westgarth C, Heron J, Ness AR, et al. Family Pet Ownership during Childhood: Findings from a UK Birth Cohort and Implications for Public Health Research. Int J Environ Res Pub Health 2010;7:3704-29. 